\title{
The Application of Classroom Simulation Exercises Teaching Method in English Pre - service Skill Training for English Teachers
}

\author{
Feng Zhiming
}

\author{
University for Science \& Technology Sichuan, Chengdu, Sichuan, China, 610101
}

Keywords: classroom simulation exercise; English teacher; pre-service skills training; application

\begin{abstract}
With the development of economic globalization, the importance of English professionals is becoming more and more prominent. English teachers, as trainers of English talents, bear important responsibilities. At present, there are many problems in the training of English teachers' pre-service skills. Classroom exercises teaching method opens up a new way for English teachers to develop pre-service skills, and there is important theoretical significance on studying the characteristics, importance and important role of classroom teaching.

With the development of China's economy and education, the demand for English professionals is getting higher and higher. English teachers, as trainers of English professionals, play an important role in the development of English. For a long time, English teacher pre-service skills training as an important work, has caused the country and society's strong attention. The emergence of classroom simulation practice teaching method has opened up a new way for English teachers 'pre-service skills training which was simulated by the real teaching environment to consolidate the basic knowledge of English teachers, to improve the teaching skills of English teachers and to improve the English teachers' professional skills [1].
\end{abstract}

\section{The Connotation and Characteristics of Classroom Simulation Exercises Teaching Method}

Classroom simulation exercise teaching method refers to a kind of method used by the teacher who design, the actual environment similar to the scene purposefully,according to the course content and purpose of the course, besides, this kind of method refers to a method used by students who can in accordance with the story of the choice of their respective roles, through different roles on the interpretation of the contents of the story, to complete the teaching tasks, and in the simulation exercises to develop their skills, with a shorter time to improve their ability.

Overall, the classroom simulation exercise method has the following characteristics: First, profession. In the classroom simulation exercise, asked the participants to have the appropriate cultural foundation, who should have a solid English skills [2]. English teachers require listening, speaking, reading, writing, translation, with good English application ability. Second, interactivity and interesting. Interactivity requires teachers to participate in classroom simulation exercises to conduct good communication. In the interaction, not only can they increase the exchange between members, but also from a different perspective solve the problem, in the process of communication to enhance themselves and increase the team's ability to cooperate. In the simulation process, the role of different roles help to mobilize the classroom atmosphere, to improve learning interest, and to cultivate the initiative of members. Third, self-knowledge. In the classroom simulation exercises, through the role of different roles, while deepening understanding of knowledge at the same time, members should increase the understanding of themselves, only to recognize their own 
shortcomings and deficiencies in can they inspire their own combat effectiveness and enhance themselves.

\section{The Existing Problems in The Current English Teachers' Pre-service Skills Training}

In the actual investigation, it is easy to find that there are some problems in the training of English teachers' pre-service skills training, which will affect the effect of English teachers' pre-service skills training. So these problems are mainly manifested in the following aspects:

The development of the times makes everyone pay more attention to the role of English in international exchanges. The goal of education in China is to cultivate a group of excellent English teachers to promote the development of English education and the improvement of English level. However, the starting point of many English teachers is not based on this great educational goal, they simply consider the wide applicability of English, therefore, in the English teacher pre-service skills training, ignoring the basic knowledge of English learning and teacher basic quality training, and there have been professional moral indifference and other issues.

Academic and normal is an important problem in the cultivation of teachers, this contradiction has a long history. In the normal education, colleges and universities attach great importance to the basic skills of teachers, therefore, teachers of various disciplines have a solid professional foundation, at the same time, colleges and universities often overlook the cultivation of teachers' scientific research ability. The scientific research capacity to adapt to social development is not enough, which makes the pre-service skills to participate in the education of teachers in the lack of passion, lack of stamina, it is difficult to adapt to the information age lifelong learning requirements [3].

\subsection{Lack of Professionalism}

The pre-service education of English teachers plays an important role in the cultivation of English teachers. However, in the process of actual training, despite the comprehensive knowledge of English, it ignores the cultivation of English teachers' professional accomplishment, which leads to the problem of lacking teachers' morality.

\section{The Importance of Classroom Simulation Exercise Teaching Method}

Classroom simulation exercises through the simulation of specific scenarios, and the interpretation of different roles can complete the teaching tasks. For the English teacher pre-service skills training, classroom simulation exercise teaching method can help English teachers to enhance their teaching ability at the same time, to exercise their own psychological quality, and to adapt to their jobs after training.

The classroom simulation exercises and the pre-class preparation and exercise process can promote English teachers to better grasp the basic theoretical knowledge and teaching methods. In the classroom simulation exercises, the English teachers can better learn to the subject-related content and grasp a solid academic foundation. English teachers can simulate their own teaching and expose their shortcomings of teaching in time to find their own problems at the same time, to absorb and learn from the advantages of other teachers, which can further improve their teaching level and their teaching skills, and lay a good foundation in the future. In addition, the English teacher in the simulation exercise by playing students and teachers and other different roles, put themselves in the role of the swap process to try to figure out the psychological activities of students and teachers from different perspectives to observe and better understand the actual needs 
of students. Only in this way, canEnglish teacher in the workplace better deal with the relationship between teachers and students and communicate with students well, to ensure the smooth progress of English teaching at the same time, to improve students' English achievement, to improve their teaching skills and to complete English teaching goals.

In the process of English teaching, teachers and students are the main body of teaching activities. Teachers play a guiding role. In the training of English teachers with the pre-service skills in the implementation of classroom simulation exercise method can increase the fun of the training process to enhance the efficiency of training and improve the enthusiasm of the participants [4]. The implementation of the simulation exercise teaching method to participate in each of the participants, in the training experience in the teaching process of fun, after-school discussion and exchange is conducive to discover their own problems, and actively correct and improve the pre-service training effect.

The practice of classroom simulation exercises can promote the enthusiasm of English teachers to prepare lessons. In the development of the exercise scene, the English teacher in accordance with the requirements of the course content, find learning materials, prepare the appropriate teaching methods and the knowledge points out, before the start of the simulation, ready to avoid in the exercise process helplessly. These preparations can train English teachers to prepare their lessons and improve their teaching skills.

\section{The Precautions of Classroom Simulation Exercise Teaching Method}

In the process of pre-service skill training for English teachers, English teachers are the center of the teaching process. Their active participation is an important factor to ensure the smooth progress of classroom simulation exercises. The training effect depends largely on the enthusiasm and input of English teachers. The higher the enthusiasm for participation, the greater the investment, the training effect will be better. Therefore, before the start of the simulation exercise, colleges and universities should take corresponding measures to stimulate the learning motivation of English teachers.

Good learning atmosphere for their own growth has a very important role, is conducive to the formation of a complete personality, is conducive to the spirit of unity and cooperation to develop. In the English teacher pre-service skills training, it is necessary to pay attention to the shaping of a good atmosphere. Before the start of the training, because the English teachers are not enough to understand each other, some games are good way to let members understand each other, deepen mutual understanding and increase the interaction between members of the interaction.

Classroom simulation exercise method is to simulate the real teaching environment, English teachers as the center, in the classroom simulation exercises to improve the English teachers of vocational skills teaching methods. In the simulation exercise, the role of English teachers need to re-positioning. In the classroom, English teachers mainly to teach English knowledge and skills. In pre-service skills training, English teachers not only need to follow the curriculum requirements for lesson preparation, explanation, but also need to act as a student, after the completion of the hearing to listen to other people's comments and suggestions, to correct, and be responsible for observing the performance of other personnel, and to organize and summarize, after the exercise, to communicate with each other, to absorb the experience of others at the same time, and to make up for their own deficiencies. English teachers should correctly position themselves, in addition to 
playing the role of teachers, but also as an audience, in the role of the exchange process, to find the problem and make up their own shortcomings [5].

In the course of teaching, the use of simulation exercises to teach, often can not harvest better results, and in the exercise process, the exercise staff can not be taken seriously from the ideological, resulting in difficult simulation exercises difficult to proceed. In fact, the classroom simulation exercise is in the classroom will be real life performance, in the simulation situation in the function of training and promotion. Therefore, the requirements of classroom simulation exercises to improve the authenticity of the situation more real, the training staff in the exercise to obtain skills to improve the harvest more learning experience. First of all, the teaching content should be connected with the actual, according to the teaching level of English teachers to allocate, for example, teaching junior high school English teachers in terms of junior high school English syllabus. Second, the teaching scene layout to be realistic. In the real environment to stimulate the enthusiasm of members, they can put heart into the simulation exercise, so as to achieve the purpose of simulation exercises.

\section{The Application of Simulation Exercise Teaching Method in the Cultivation of English Teachers' Pre-service Skills}

The classroom simulation exercise method provides a new scheme for the cultivation of English teachers' skills, and puts forward higher requirements for English teachers. In the pre-service skills training, English teachers should not only master the basic knowledge of English, but also have the appropriate teaching skills [6]. The practice of classroom simulation exercises is a good solution to solve this problem, pre-service training, through the simulation exercises to train English teachers teaching ability, in the actual exercise to find their own problems, and from other people who learn the corresponding of the teaching skills.

As the saying goes: no rules, not a radius The smooth implementation of classroom simulation exercises requires a strict system as a guarantee. Therefore, the English teacher pre-service skills training should develop a sound simulation system, with a clear provision of the various aspects of the exercise, so that each member from the ideological attention. In addition, the layout of the simulation scene to meet the actual requirements, close to the teaching practice.

In the simulation exercise, the English teacher's skills can be improved, and in the exercise their overall level also can be improved. The comprehensive simulation test is very necessary. The training party may conduct a comprehensive test according to the cycle or according to the number of simulated exercises, invite the professional education experts as the review. The English teacher should practice according to the expert's request, followed by the expert comment, and then the outstanding performance should be rewarded, to stimulate the enthusiasm of all English teachers , and to improve the simulation exercise effect.

Classroom simulation exercise method opens up a new way for the improvement of English teachers, in the promotion of pre-service skills at the same time it is necessary to pay more attention to the cultivation of teachers. As the saying goes: for the teacher, only with good character and mettle, in order to truly reflect the professional quality of teachers. Parents or teachers will have an important impact on the students gradually, therefore, in the promotion of English teachers preservice skills at the same time, we should pay attention to the cultivation of English teachers morality, to establish relevant incentives to form a good morality atmosphere. 
Classroom simulation of the practice of teaching method bring new changes for the English teacher pre-service skills and have a significant impact on teaching content and teaching methods. By simulating the real classroom environment and cultivating English teachers' teaching skills, it is an effective teaching method to consolidate the basic knowledge of English teachers. In the use of this teaching method to develop English teachers pre-service skills, not only to focus on the motivation of English teachers to stimulate, but also to create a good training atmosphere, pay attention to the moral and quality of the shape, in addition, to improve classroom simulation exercise and teaching mechanism to ensure the smooth progress of the exercise process. Only in this way, can the importance of classroom practice teaching method continue to strengthen, the application will also be more extensive.

\section{References:}

[1] Xing Yaqian. English Teachers Pre-service Education Practice Course Survey and Reform Strategy [D]. Xi'an Foreign Studies University, 2013.

[2] Han Rui. Hong Kong Primary and Secondary School English Teachers Pre-service Training Model Reform [D]. Capital Normal University, 2011.

[3] Xu Yongjun, Wang Fujuan. The Construction of Preschool Teacher's Pre-service Training Model - Taking Pre-school Education Students as an Example [J]. Journal of Shangrao Normal University, 2014, 01: 114-118.

[4] Wang Peipei. Primary School English Teachers Pre-teaching Skills Training Research [J]. Journal of Taiyuan University, 2014, 01: 100-102. 